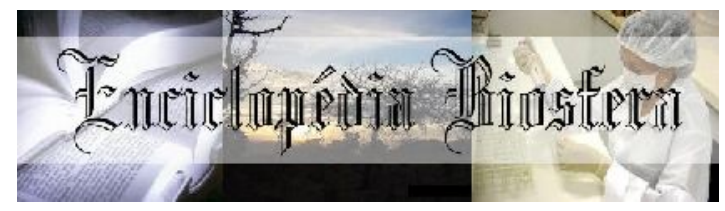

\title{
ESTUDO DA COLONIZAÇÃO MICORRÍZICA ARBUSCULAR NO DESENVOLVIMENTO DE MINIROSA NO MUNICÍPIO DE EUSÉBIO-CE
}

\author{
Maria Eloneide de Jesus Bezerra ${ }^{1}$, Paulo Furtado Mendes Filho ${ }^{2}$, Kaio Gráculo Vieira \\ Garcia $^{3}$, Vânia Felipe Freire Gomes ${ }^{2}$ \\ 1 Mestre em Agronomia / Solos e Nutrição de Plantas - Universidade Federal do \\ Ceará. \\ 2 Professor (a) Doutor (a) Titular do Departamento de Ciências do Solo - \\ Universidade Federal do Ceará. \\ 3 Doutorando em Ciência do Solo, Universidade Federal do Ceará \\ (kaiovieira88@hotmail.com), Fortaleza - Brasil
}

Recebido em: 06/04/2018 - Aprovado em: 10/06/2018 - Publicado em: 20/06/2018 DOI: 10.18677/EnciBio_2018A45

\begin{abstract}
RESUMO
O Estado do Ceará vem se destacando na área de produção de flores e plantas ornamentais nos últimos anos e tem apresentado crescimento em vários aspectos. Apesar disso, há uma grande carência de pesquisas sobre essas flores no país, bem como sobre as possíveis associações benéficas com micro-organismos edáficos. Objetivou-se neste estudo avaliar o efeito da colonização micorrízica arbuscular sobre o desenvolvimento de minirosa em um Neossolo Quartzarênico do município de Eusébio no Estado do Ceará. O experimento foi conduzido, inicialmente, em miniestufa e posteriormente em condições de campo, após o processo de transplantio, em Eusébio-CE. O delineamento experimental foi inteiramente casualizado, em esquema fatorial 2 (dois níveis de fósforo) x 2 (enraizamento em solo estéril e natural) x 2 (irrigação com água da lagoa natural e água da lagoa estéril), com 3 repetições. Aos 90 dias após o transplantio foram avaliados: altura da parte aérea $(\mathrm{cm})$, matéria seca da parte aérea $(\mathrm{g})$, número de esporos de fungos micorrízicos arbusculares (FMA) no solo (esporos/100 $\mathrm{g}^{-1}$ ), colonização micorrízica (\%), ocorrência das estruturas de FMA observadas nas raízes e número de rosas (NR). A associação micorrízica arbuscular em minirosa é importante para o desenvolvimento das plantas em solos com baixa disponibilidade de P. A irrigação com água de lagoa natural não interfere na colonização micorrízica arbuscular de minirosa. A espécie Rosa chinensis é de baixa colonização micorrízica, mas responde à micorrização, visto que a colonização precoce aumentou de forma significativa a matéria seca da parte aérea.
\end{abstract}

PALAVRAS-CHAVE: fósforo, micorriza, rosas. 


\title{
STUDY OF ARBUSCULAR MYCORRHIZAL COLONIZATION IN THE DEVELOPMENT OF MINIROSA IN THE MUNICIPALITY OF EUSÉBIO-CE
}

\begin{abstract}
The State of Ceará it has excelled in the area of flowers and ornamental plants in recent years and has shown growth in several aspects. Despite this, there is a great lack of research on these flowers in the country, as well as on the possible beneficial associations with edaphic microorganisms. The objective of this study was to evaluate the effect of arbuscular mycorrhizal colonization on the development of minirosa in a Quartzarenic Neosol of the municipality of Eusebio in the State of Ceará. The experiment was conducted initially in mini-greenhouses and later in field conditions, after the transplanting process, in Eusébio-CE. The experimental design was completely randomized, in a factorial scheme: 2 (two levels of phosphorus) $\times 2$ (rooting in sterile or natural soil) $\times 2$ (irrigation with water from the natural pond or water from the sterile pond), with 3 replicates. To the 90 days after transplanting were evaluated: aerial part height, shoot dry matter, number of spores of arbuscular mycorrhizal fungi (AMF) in the soil, Mycorrhizal colonization, occurrence of AMF structures observed in roots and number of roses. The arbuscular mycorrhizal association in minirosa is important for the development of plants in soils with low availability of $P$. The irrigation with natural pond water does not interfere in the arbuscular mycorrhizal colonization of minirosa. The species Rosa chinensis is of low mycorrhizal colonization, but it responds to mycorrhization, since early colonization significantly increased the dry matter production of the aerial part.
\end{abstract}

KEYWORDS: Roses, mycorrhiza, phosphorus.

\section{INTRODUÇÃO}

No Brasil, a comercialização de flores e plantas ornamentais está em considerável crescimento (JUNQUEIRA; PEETZ, 2014), pois em todo país estão sendo implementados pólos regionais de produção atualmente caracterizados pelo uso de novas tecnologias buscando, desta forma, atender às exigências internacionais quanto à qualidade, padronização e pós-colheita. Estes fatores irão beneficiar o consumidor brasileiro, que assim terá acesso a produtos de melhor qualidade e preços cada vez mais compatíveis com a realidade brasileira.

A produção de rosas é uma atividade bastante importante em regiões como Barbacena e Andradas em Minas Gerais, Holambra e Atibaia no estado de São Paulo, onde um grande número de famílias depende dessa cultura, no Nordeste, a região de Vitória da Conquista no meio Oeste da Bahia destaca-se no cultivo de rosas em estufas e campo e também no Ceará no Distrito de Inhuçú, São Benedito (SEVERINO, 2007).

Novos produtos estão sendo incorporados à pauta das exportações cearenses sendo um deles a floricultura que tem nos bulbos e tubérculos e nas rosas os exemplos mais representativos. O Ceará vem se destacando na produção de flores e plantas ornamentais e apresentando crescimento quanto à área cultivada, valor da produção, volume e quantidade exportados, dentre outros aspectos, influenciando, dessa maneira, no desenvolvimento da economia cearense e na geração de empregos e renda. Segundo informações obtidas através da Agência do Desenvolvimento do Estado do Ceará (ADECE, 2017), até 2009 o Ceará ocupou o $2^{\circ}$ lugar nas exportações de flores dentro do ranking das exportações dos 
principais agronegócios do Ceará. O Ceará ocupa, ainda, a posição de primeiro exportador de rosas do Brasil (INSTITUTO AGROPOLOS, 2017).

No entanto, apesar da grande importância econômica das rosas no Ceará como também em outros estados do Brasil, há carência de pesquisas sobre essas flores no país (DUVAL, 2014). Muito do manejo adotado pelos produtores de rosas no Ceará ainda está fundamentado em uma experimentação baseada em tentativas de acerto, não existindo pesquisas ordenadas que gerem tecnologia apropriada às nossas condições edafo-climáticas. As informações são escassas quanto, por exemplo, às exigências nutricionais de roseiras nas condições de produção no Brasil, bem como sobre as possíveis associações benéficas estabelecidas com microrganismos edáficos.

Os fungos micorrízicos arbusculares (FMA) são micro-organismos capazes de formar associação simbiótica com a maioria das plantas terrestres (KÖHL; VAN DER HEIJDEN, 2016; STOFFEL et al., 2016). Conhecidos por atuar na melhoria nutricional das plantas, principalmente em relação aos nutrientes de baixa mobilidade, como no caso do fósforo, os FMA também podem atuar na adaptação das plantas a estresses bióticos e abióticos do solo (COLODETE et al., 2014; MARTINS et al., 2017; SOARES et al., 2017).

Nesse sentido, a otimização da produção mediante a associação com FMA seria relevante, pois promovendo melhor crescimento da planta colonizada em função do uso mais eficiente de água e do maior aproveitamento de nutrientes, principalmente fósforo, resultaria em aumento da produtividade do viveiro e diminuição dos gastos com fertilizantes e agroquímicos determinando, como consequência, uma redução nos custos de produção.

Considerando a importância econômica da produção de algumas espécies de rosa no Brasil, os poucos trabalhos de pesquisa desenvolvidos na área da floricultura e a relevância da relação simbiótica estabelecida entre FMA e várias espécies de plantas, objetivou-se nesse trabalho avaliar o efeito da colonização micorrízica arbuscular sobre o desenvolvimento de minirosa em um Neossolo Quartzarênico do município de Eusébio no Estado do Ceará.

\section{MATERIAL E MÉTODOS}

O experimento foi conduzido, inicialmente, em mini-estufa e posteriormente em condições de campo, após o processo de transplantio, no município de Eusébio, Ceará (Latitude $3^{\circ} 53^{\prime} 24^{\prime \prime} S$ e Longitude 38²7'02'W), por um período de 90 dias. O clima da região é classificado como tropical, com temperatura e precipitação médias anuais de $29^{\circ} \mathrm{C}$ e $1350 \mathrm{~mm}$, respectivamente.

O delineamento experimental utilizado foi inteiramente casualizado, em arranjo fatorial $2 \times 2 \times 2$, considerando-se i) dois níveis de fósforo (ótimo e sub ótimo), ii) duas condições de enraizamento (em solo estéril e natural), iii) duas condições de água para irrigação (irrigação com água da lagoa natural e estéril), com três repetições, totalizando 24 unidades experimentais.

O solo utilizado foi coletado a uma profundidade de $0-20 \mathrm{~cm}$, o qual foi classificado como Neossolo Quartzarênico (EMBRAPA, 2006).

Após a coleta foi realizado um peneiramento em malha de $2 \mathrm{~mm}$, com objetivo de retirar parte do material mais grosseiro do solo. As características químicas foram determinadas de acordo com os procedimentos descritos pelo manual da Empresa Brasileira de Pesquisa Agropecuária (EMBRAPA, 1997) e encontram-se presentes na Tabela 1. 
TABELA 1. Características químicas do solo utilizado no experimento (estéril e natural).

\begin{tabular}{|c|c|c|c|c|c|c|c|c|c|c|c|c|}
\hline $\mathrm{Ca}^{2+}$ & $\mathrm{Mg}^{2+}$ & $\mathrm{Na}^{+} \quad \mathrm{K}^{+}$ & $\mathrm{H}+\mathrm{Al}^{3+}$ & $\mathrm{Al}^{+}$ & V & $\mathrm{m}$ & PST & C & $\mathrm{N}$ & MO & $P$ & $\mathrm{pH}$ \\
\hline & -- & cmolc.kg ${ }^{-1}$ & 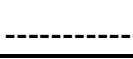 & --- & $(\%)$ & (\% & & g. $\mathrm{kg}^{-1}$ & -----. & $\mathrm{mg} \cdot \mathrm{kg}$ & 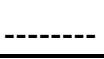 & $\mathrm{H}_{2} \mathrm{O}$ \\
\hline 1,00 & 0,60 & $\begin{array}{lll}0,06 & 0,08\end{array}$ & 1,98 & 0,20 & 46 & 1 & 2 & 5,58 & 0,56 & 9,62 & 3 & 5,6 \\
\hline
\end{tabular}

As estacas de minirosa (Rosa chinensis) foram obtidas de roseira com idade de aproximadamente 12 meses. As estacas foram plantadas, inicialmente, em bandejas (cada célula recebeu uma estaca) contendo solo estéril e solo natural. $O$ solo estéril não sofreu alterações químicas após o processo de esterilização, apresentando assim as mesmas características químicas do solo natural (Tabela 1). As estacas foram mantidas por um período de 30 dias, tempo estimado para a ocorrência do enraizamento com ou sem espécies nativas de FMA. Estas estacas também receberam água de lagoa estéril e natural (conforme a disposição dos fatores de tratamento) durante o período de formação de raízes. A fase de enraizamento das estacas ocorreu em mini-estufa.

As irrigações com água natural ou estéril foram realizadas diariamente de modo a manter a umidade do solo contida nas células da bandeja. Durante o período de enraizamento as estacas receberam apenas nutrientes oriundos da água de lagoa ou através do solo. Após os 30 dias estimados para o enraizamento, antes do transplantio as plantas foram submetidas ao processo de aclimatação durante 7 dias com o objetivo de adaptar as mudas ao novo ambiente. A solução nutritiva passou a ser aplicada apenas após o transplantio das mudas para os vasos plásticos. Após o transplantio, as mudas não mais receberam água estéril e foram todas transplantadas para solo apenas natural.

Após o período de formação de raízes, todas as mudas foram transplantadas para vasos plásticos de $400 \mathrm{~mL}$ de capacidade (cada vaso recebeu uma muda) contendo solo apenas natural onde também passaram a receber água de lagoa apenas natural e dois níveis de fósforo através da aplicação de solução nutritiva. As irrigações com água natural, após o transplantio, foram realizadas diariamente de modo a manter a umidade do solo. A irrigação foi realizada por aspersão. As características químicas da água de irrigação estão apresentadas na tabela 2.

TABELA 2. Análise química da água de lagoa.

\begin{tabular}{|c|c|c|c|c|c|c|c|c|c|c|}
\hline $\begin{array}{c}\mathrm{pH} \\
\mathrm{H}_{2} \mathrm{O}\end{array}$ & $\begin{array}{c}\text { CE } \\
\text { dS. } m^{-1}\end{array}$ & RAS & $\mathrm{Ca}^{2+}$ & $\begin{array}{l}\mathrm{Mg}^{2+} \\
-(\mathrm{mmolc}\end{array}$ & $\begin{array}{c}\mathrm{Na}^{+} \\
\left.\mathrm{L}^{-1}\right)\end{array}$ & $\mathrm{K}^{+}$ & $\mathrm{Cl}^{-}$ & $\begin{array}{c}\mathrm{SO}_{4}{ }^{2-} \\
---\mathrm{mmolc} . \mathrm{L}\end{array}$ & ${ }_{-1} \mathrm{HCO}^{3-}$ & $\begin{array}{c}\mathrm{MO} \\
\left(m g \cdot L^{-1}\right)\end{array}$ \\
\hline 6,8 & 0,24 & 01 & 0,8 & 0,7 & 0,9 & 0,1 & 1,6 & 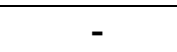 & 0,8 & 5,13 \\
\hline
\end{tabular}

Após o transplantio, procurou-se verificar se o enraizamento em solo natural promoveria algum tipo de vantagem (maior sobrevivência ao transplantio ou melhor desenvolvimento das plantas colonizadas por FMA no enraizamento) nas plantas que chegassem às condições de campo já pré-colonizadas em relação às plantas enraizadas em solo estéril, ou seja, enraizadas na ausência de FMA. Além do fator solo, buscou-se observar se a água de lagoa poderia de alguma forma suprir a planta, não colonizada precocemente, da ausência da micorríza, pois são muitos os benefícios (já citados anteriormente) trazidos por essa simbiose.

Nos tratamentos onde o enraizamento ocorreu em solo estéril este foi autoclavado à temperatura de $121^{\circ} \mathrm{C}$ e a uma pressão de $1 \mathrm{~atm}$ durante 2 horas com a finalidade de eliminar toda microbiota viável presente. Em relação a irrigação realizada no período de formação de raízes, nos tratamentos onde as estacas receberam água esterilizada durante o período de enraizamento, a esterilização foi 
realizada por um período de 30 minutos de autoclavagem à uma temperatura de $121^{\circ} \mathrm{C}$ e a uma pressão de $1 \mathrm{~atm}$.

No cultivo das plantas, a solução nutritiva de Hoagland foi utilizada na adubação. No entanto, sua composição foi modificada, pela redução do fósforo $(P)$. A redução do $P$ foi realizada com o objetivo de estimular a associação micorrízica, pois se sabe que a concentração de fosfato $(P)$ no solo é um fator determinante para essa simbiose. Com base na análise química do solo, foram determinadas as concentrações de fósforo a serem aplicadas. Para tanto, adicionou-se às parcelas a solução nutritiva de Hoagland em $100 \%$ e $50 \%$ de sua força iônica correspondendo, respectivamente, aos níveis de fósforo $\mathrm{P}_{1}$ (nível ótimo) e $\mathrm{P}_{2}$ (nível subótimo). As aplicações foram realizadas três vezes por semana (60 mL/planta/semana) em todos os vasos sendo fornecidos $0,051 \mathrm{~g} /$ planta ( $\mathrm{P}$ ótimo) e $0,026 \mathrm{~g} /$ planta ( $\mathrm{P}$ subótimo) de fósforo na forma de $\mathrm{P}_{2} \mathrm{O}_{5}$. $\mathrm{A}$ adubação foi iniciada apenas 20 dias após o transplantio (DAT).

Aos 90 DAT foram avaliados os seguintes parâmetros: altura da parta aérea (ALTPA), mensurada através de uma régua milimétrica; matéria seca da parte aérea (MSPA), determinada após secagem em estufa a 65ํㅡ, até peso constante; número de esporos de FMA no solo (NumEsp), determinado através da extração pela técnica do peneiramento úmido, conforme descrito por Gerdermann e Nicolson (1963); colonização micorrízica (CM), determinada pelos procedimentos metodológicos descritos por Koske e Gemma (1989), sendo a percentagem de colonização obtida de acordo com Mcgonigle et al. (1990), ocorrência de estruturas de FMA nas raízes (somente identificação dos tipos de estruturas formadas nas raízes, não analisado estatisticamente) e número de rosas (NR), por meio de contagem direta.

Os dados obtidos foram submetidos a análise de variância usando o programa estatístico SAS ${ }^{\circledR}$ (SAS, 1988), através do teste $F(p<0,05)$, e testes de médias através do teste $t$ de Student $(p<0,05)$ para desdobramento das interações significativas.

\section{RESULTADOS E DISCUSSÃO}

No presente estudo, observou-se que o desenvolvimento da minirosa (Rosa chinensis) foi influenciado significativamente $(p<0,05)$ pelos níveis de fósforo, pelas condições de enraizamento (solo estéril e natural) e pelo tipo de água de irrigação. A influência desses fatores foi manifestada de forma isolada ou através da interação entre eles (Tabela 3).

TABELA 3. Resumo da análise de variância para altura da parte aérea (ALTPA), matéria seca da parte aérea (MSPA), colonização micorrízica (CM), número de esporos de FMA no solo (NumEsp) e número de rosas (NR).

\begin{tabular}{|c|c|c|c|c|c|}
\hline Fonte de variação & $\overline{\text { ALTPA }}$ & MSPA & $\overline{C M}$ & NumEsp & $\overline{N R}$ \\
\hline \multicolumn{6}{|c|}{$\mathrm{Pr}>\mathrm{F}$} \\
\hline$P$ & ns & ns & $0,0090^{* *}$ & ns & ns \\
\hline ENRZ & ns & $0,0372^{*}$ & ns & $0,0025^{* *}$ & ns \\
\hline IRRIG & ns & ns & ns & ns & ns \\
\hline$P \times E N R Z$ & ns & $0,0372^{*}$ & ns & ns & ns \\
\hline$P \times I R R I G$ & ns & $0,0042^{* *}$ & ns & ns & ns \\
\hline$E N R Z \times$ IRRIG & ns & $0,0012^{* *}$ & ns & ns & ns \\
\hline PxENRZxIRRIG & ns & ns & ns & ns & ns \\
\hline $\mathrm{CV} \%$ & 12,98 & 12.71 & 59.9 & 11.53 & 90,52 \\
\hline
\end{tabular}

${ }^{*}$ Significativo $(p<0,05)$ pelo Teste $F,{ }^{* *}$ Significativo $(p<0,01)$ pelo Teste $F, n s=$ não significativo

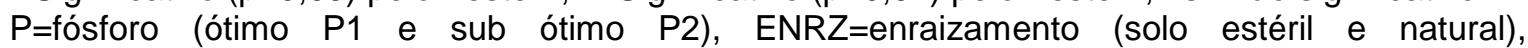
IRRIG=irrigação (água de lagoa natural e estéril). 
Para MSPA houve efeito significativo $(p<0,05)$ (Tabela 3$)$ das condições de enraizamento, o qual foi fator determinante na produção de MSPA das plantas, além das interações significativas $(p<0,05)$ (Tabela 3$)$ observadas entre os fatores de tratamento: $P$ x ENRZ, P x IRRIG e ENRZ x IRRIG.

Ao analisar a interação $P \times E N R Z$ (Figura 1), observou-se que nas plantas que receberam o nível ótimo $(\mathrm{P} 1)$ de fósforo não houve diferença estatística significativa $(p<0,05)$ do tipo de enraizamento das estacas, em solo natural ou estéril, sobre o aumento da produção de MSPA das plantas. Portanto, o enraizamento com pré-colonização promoveu o mesmo efeito do enraizamento na ausência da microbiota nativa do solo na produção de MSPA, considerando as plantas que receberam o maior aporte de fósforo (P1).

Nas plantas que receberam o nível subótimo (P2), a colonização precoce aumentou de forma significativa a produção de MSPA de plantas enraizadas em solo natural em relação às plantas enraizadas em solo estéril (Figura 1). Não foi encontrada diferença significativa na MMSPA quando se comparou entre o fator níveis de $P$ dentro de cada tipo de enraizamento (Figura 1).

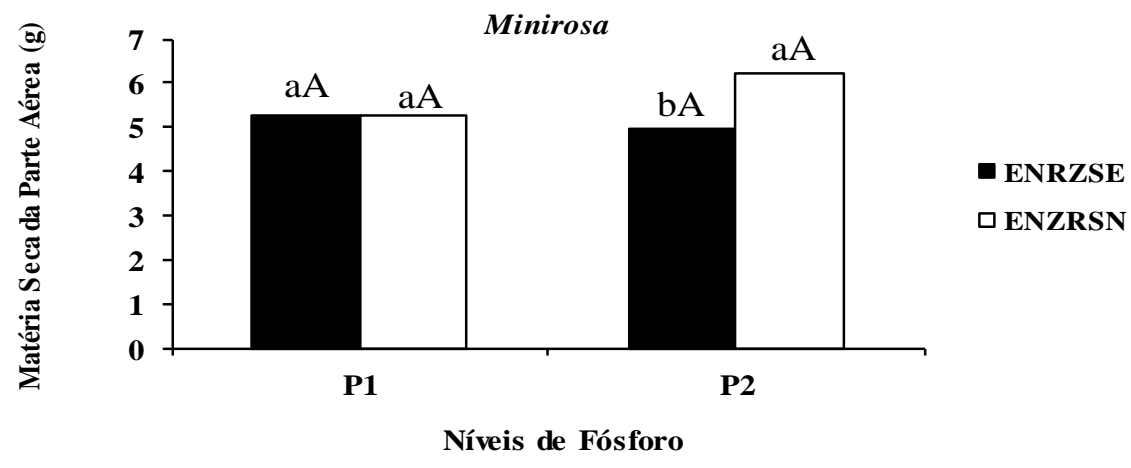

FIGURA 1. Efeito da interação $P$ (P1 nível ótimo e $P 2$ sub ótimo de fósforo) x ENRZ (ENRZSE= enraizamento em solo estéril e ENRZSN = enraizamento em solo natural) sobre a produção de matéria seca da parte aérea (MSPA) em plantas de minirosa aos 90 DAT. Médias seguidas pelas mesmas letras minúsculas entre os tipos de enraizamento dentro de cada nível de $P$, e maiúsculas entre os níveis de $\mathrm{P}$ dentro de cada tipo de enraizamento, não diferem estatisticamente entre si pelo teste $t$ de student $(p<0,05)$.

Esse fato sugere que os FMA podem ter sido estimulados pelo menor suprimento de fósforo (já que um dos fatores determinantes da associação é a nutrição mineral), pois o fator $\mathrm{P}$ foi o único a promover, isoladamente, efeito sobre a colonização micorrízica. Normalmente, altas concentrações de P na planta inibem a colonização das raízes, enquanto baixas concentrações favorecem a colonização intrarradicular (MOREIRA; SIQUEIRA, 2006; SILVA et al., 2016).

Resultados semelhantes também foram observados por Miranda et al. (2016) ao trabalharem com inoculação micorrízica e adubação fosfatada na produção de mudas de Amendoim Forrageiro. Esses autores relatam que as mudas colonizadas 
por FMA proporcionaram aumento de massa seca da parte aérea nas menores doses de $\mathrm{P}$, atingindo um ponto de máximo e caindo nas maiores doses. Por outro lado, Cruz et al. (2017) ao estudarem o crescimento de Ruta graveolens L. inoculada com micorrizas arbusculares sob dois níveis de $P$, observaram incremento na matéria seca da parte aérea em plantas inoculadas com Rizophagus clarus sob nível máximo de $\mathrm{P}\left(200 \mathrm{mg} \mathrm{kg}^{-1}\right)$ aplicado ao solo. Diferentes respostas podem variar com os níveis de $\mathrm{P}$ e outras condições do solo, a espécie de FMA presente e com a cultivar ou espécie de planta (CARDOSO et al., 2010; BRITO et al., 2017).

Avaliando o comportamento da interação $P \times I R R I G$ (Figura 2), verificou-se que as plantas que foram tratadas com o maior nível de fósforo ( $\mathrm{P} 1)$ e água estéril apresentaram aumento significativo $(p<0,05)$ (Tabela 3$)$ de MSPA em relação àquelas que foram irrigadas com água natural. Todavia, para as plantas supridas com menos fósforo (P2) e água natural o efeito sobre a produção de MSPA foi maior do que quando se aplicou água estéril. Isto sugere que os microrganismos presentes na água natural tenham contribuído para a maior influência da interação entre P2 e a irrigação com água natural. Ao analisar entre o fator níveis de $\mathrm{P}$ dentro de cada tipo de irrigação, observa-se que as plantas irrigadas com água de lagoa natural com nível de $\mathrm{P}$ sub ótimo (P2), proporcionaram aumento significativo na MSPA quando comparado as plantas irrigadas com água de lagoa natural com nível de $P$ ótimo (P1) (Figura 2).

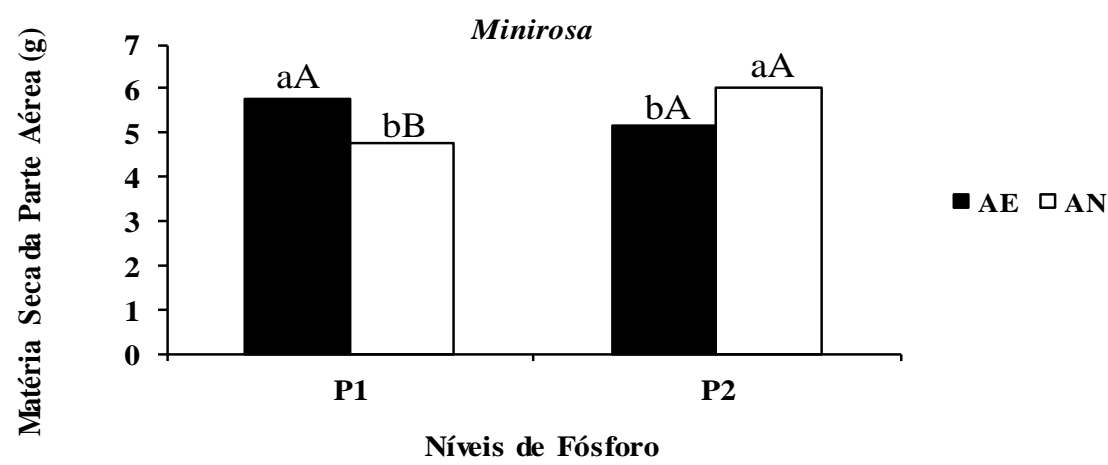

FIGURA 2. Efeito da interação $P$ (P1 nível ótimo e $P 2$ sub ótimo de fósforo) $x$ IRRIG (AE = irrigação com água de lagoa estéril e $\mathrm{AN}$ = irrigação com água de lagoa natural) sobre a produção de matéria seca da parte aérea (MSPA) em plantas de minirosa aos 90 DAT. Médias seguidas pelas mesmas letras minúsculas entre os tipos de irrigação dentro de cada nível de $\mathrm{P}$, e maiúsculas entre os níveis de $\mathrm{P}$ dentro de cada tipo de irrigação, não diferem estatisticamente entre si pelo teste $t$ de student $(p<0,05)$.

Ao realizar o desdobramento da interação ENRZ x IRRIG (Figura 3), verificouse que o efeito do enraizamento em solo estéril foi maior quando se utilizou água também estéril. Isso sugere que pode ter ocorrido uma forma de compensação dos FMA, ou seja, uma maior contribuição da micorriza para a superação das plantas sob condições de privação simbiótica durante o período de formação de raízes, 
podendo indicar também, dessa forma, o maior requerimento da associação com FMA pela planta.

O enraizamento em solo natural teve maior influência na MSPA quando se aplicou água natural. O maior potencial biológico, oriundo da água natural e do solo natural, pode ter contribuído para o aumento da produção de MSPA (Figura 3). Ao analisar entre o fator tipo de enraizamento dentro de cada tipo de irrigação, observase que somente as plantas irrigadas com água de lagoa natural e enraizadas em solo natural proporcionaram aumento significativo na MSPA, quando comparado as plantas irrigadas com água de lagoa natural e enraizadas em solo estéril (Figura 3).

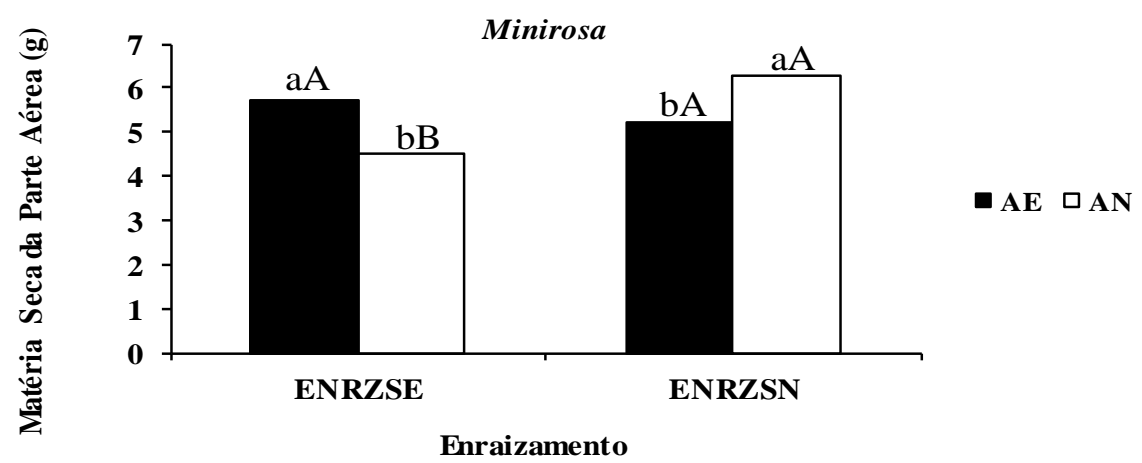

FIGURA 3. Efeito da interação ENRZ (ENRZSE = enraizamento em solo estéril e ENRZSN = enraizamento em solo natural) $x$ $\operatorname{IRRIG}(A E$ = irrigação com água de lagoa estéril e $A N$ = irrigação com água de lagoa natural) sobre a produção de matéria seca da parte aérea (MSPA) em plantas de minirosa aos 90 DAT. Médias seguidas pelas mesmas letras minúsculas entre os tipos de irrigação dentro de cada tipo de enraizamento, e maiúsculas entre os tipos de enraizamento dentro de cada tipo de irrigação, não diferem estatisticamente entre si pelo teste $t$ de student $(p<0,05)$.

Em relação à colonização micorrízica, o fósforo foi, estatisticamente, o único fator a influenciar nos resultados quanto a esta variável. No nível sub ótimo de fósforo P2 (50\%) as plantas apresentaram maior colonização micorrízica quando comparadas ao nível ótimo de fósforo P1 (100\%) (Tabela 4).

TABELA 4. Efeito do fator $P$ (P1 = nível ótimo e $P 2$ = sub ótimo de fósforo) sobre a colonização micorrízica (CM) em plantas de minirosa aos 90 DAT.

\begin{tabular}{cc}
\hline $\mathrm{P}$ & $\mathrm{CM}$ \\
\cline { 2 - 2 } & $(\%)$ \\
\hline P1 & $4,81 \% \mathrm{~b}$ \\
P2 & $14,80 \% \mathrm{a}$ \\
\hline
\end{tabular}

Médias seguidas pela mesma letra não diferem estatisticamente entre si pelo teste $t$ de student $(p<0,05)$.

Geralmente, quando o ambiente é estressante para a planta, com baixo suprimento de água e de nutrientes, particularmente de $\mathrm{P}$, geralmente a simbiose micorrízica arbuscular garante benefícios para a planta, como a melhoria na absorção de nutrientes e, consequentemente, no crescimento das plantas (HEITOR 
et al., 2016). Por outro lado, a elevação do fósforo disponível no solo além de reduzir a colonização das raízes pode diminuir a esporulação e a diversidade dos fungos micorrízicos (NASCIMENTO et al., 2016).

Nas raízes coradas de minirosa não foi observada a presença de qualquer estrutura fúngica semelhante a arbúsculos. Por outro lado, foram encontradas uma grande profusão de hifas endofíticas, esporos e vesículas que, de acordo com a predominância de ocorrência, distribuíram-se conforme descrito na tabela 5.

TABELA 5. Ocorrência das estruturas de FMA observadas nas raízes de minirosas colonizadas.

\begin{tabular}{cccc}
\hline Tratamentos $^{1}$ & Micélio & Vesícula & Esporo \\
\hline P1 + Enrz. Solo Nat. + Água Nat. & $\mathrm{M}$ & $\mathrm{B}$ & $\mathrm{M}$ \\
P2 + Enrz. Solo Nat. + Água Nat. & $\mathrm{M}$ & $\mathrm{B}$ & $\mathrm{B}$ \\
P1 + Enrz. Solo Nat. + Água Est. & $\mathrm{B}$ & $\mathrm{M}$ & $\mathrm{M}$ \\
P2 + Enrz. Solo Nat. + Água Est. & $\mathrm{A}$ & $\mathrm{B}$ & $\mathrm{M}$ \\
P1 + Enrz. Solo Est. + Água Nat. & $\mathrm{A}$ & $\mathrm{B}$ & $\mathrm{M}$ \\
P2 + Enrz. Solo Est. + Água Nat. & $\mathrm{A}$ & $\mathrm{B}$ & $\mathrm{B}$ \\
P1 + Enrz. Solo Est. + Água Est. & $\mathrm{A}$ & $\mathrm{B}$ & $\mathrm{M}$ \\
P2 + Enrz. Solo Est. + Água Est. & $\mathrm{A}$ & $\mathrm{B}$ & $\mathrm{M}$ \\
\hline
\end{tabular}

${ }^{1}$ As estruturas fúngicas foram interpretadas quanto a ocorrência (Alta=A, Média=M e Baixa=B). $\mathrm{P}=$ fósforo, Enrz.=enraizamento, Nat. = natural, Est.=estéril

Para a variável número de esporos, o tipo de enraizamento foi o principal fator responsável pelo efeito na esporulação não havendo, dessa maneira, interação significativa $(p>0,05)$ entre os demais fatores de tratamento (Tabela 3$)$. O tratamento ENRZSN apresentou número de esporos significativamente superior ao tratamento ENRZSE (Tabela 6).

TABELA 6. Efeito do fator ENRZ (ENRZSE = enraizamento em solo estéril e ENRZSN = enraizamento em solo natural) sobre o número de esporos de FMA em plantas de minirosa aos 90 DAT.

\begin{tabular}{cc}
\hline \multirow{2}{*}{ ENRZ } & Número de Esporos de FMA \\
\cline { 2 - 2 } ENRZSE & (esporos/100 g de solo) \\
ENRZSN & $5639,06 \mathrm{~b}$ \\
\hline
\end{tabular}

Médias seguidas pela mesma letra não diferem estatisticamente entre si pelo teste $t$ de student $(p<0,05)$.

A esporulação na rizosfera da minirosa foi caracterizada pela alta predominância de esporos típicos do gênero Glomus. Foram encontrados, também, esporos do gênero Gigaspora, porém, em quantidade expressivamente menor. Observação semelhante foi realizada por Santos et al. (2013) em experimento realizado com diferentes coberturas florestais em Vitória da Conquista, Bahia e por Dantas et al. (2015) estudando a diversidade de fungos micorrízicos arbusculares em pomar orgânico, no semiárido cearense. Respostas como essa, possivelmente, podem indicar a capacidade adaptativa desse gênero, em detrimento de outros, as condições ambientais dessas regiões. 


\section{CONCLUSÕES}

$\mathrm{O}$ enraizamento em solo natural promove um maior desenvolvimento da minirosa no solo com menos $\mathrm{P}$ disponível;

A associação micorrízica arbuscular em minirosa parece ser importante para o desenvolvimento das plantas em solos com baixa disponibilidade de $\mathrm{P}$;

A irrigação com água de lagoa natural não interferiu na colonização micorrízica arbuscular de minirosa;

A espécie Rosa chinensis é de baixa colonização micorrízica, mas responde à micorrização, visto que a colonização precoce aumentou de forma significativa a produção de matéria seca da parte aérea.

Mais pesquisas devem ser realizadas no sentido de se entender melhor as interações biológicas que ocorrem com a Rosa chinensis no solo.

\section{REFERÊNCIAS}

ADECE. Agência do Desenvolvimento do Estado do Ceará (2017). Disponível em: <http:// http://www.adece.ce.gov.br>. Acesso: 22 de novembro de 2017.

BRITO, V. N.; TELLECHEA, F. R. F.; HEITOR, L. C.; FREITAS, M. S. M.; MARTINS, M. A. Fungos micorrízicos arbusculares e adubação fosfatada na produção de mudas de paricá. Ciência Florestal, v. 27, n. 2, p.485-497, 2017. Disponível em: <http://dx.doi.org/10.5902/1980509827730>. doi: 10.5902/1980509827730.

CARDOSO, E. J. B. N.; CARDOSO, I. M.; NOGUEIRA, M. A.; MALUCHE-BARETTA, C. R. D.; PAULA, A. M. Micorrizas arbusculares na aquisição de nutrientes pelas plantas. In: SIQUEIRA, J. O.; SOUZA, F. A.; CARDOSO, E. J. B. N.; TSAI, S. M. (ed.) Micorrizas: $\mathbf{3 0}$ anos de pesquisas no Brasil. Lavras: UFLA, 2010. 716p.

COLODETE, C. M.; DOBBSS, L. B.; RAMOS, A. C. Aplicação das micorrizas arbusculares na recuperação de áreas impactadas. Natureza On Line, v. 12, n. 1, p.31-37, $2014 . \quad$ Disponível em: <http://www.naturezaonline.com.br/natureza/conteudo/pdf/05_ColodeteCMetal_031037.pdf>.

CRUZ, R. M. S.; MARCHI, B. de A.; SOUZA, B. C. de; SOUZA, J. S. de; BELTRAME, S. R.; et al. Crescimento de Ruta graveolens L. inoculada com micorrizas sob doses de fósforo. Arquivos de Ciências Veterinárias e Zoologia da Unipar, v. 20, n. 1, p.23-27, 2017. Disponível em: <https://doi.org/10.25110/arqvet.v20i1.2017.6316>. 10.25110/arqvet.v20i1.2017.6316.

DANTAS, B. L.; WEBER, O. B.; NETO, J. P. M.; ROSSETTI, A. G.; PAGANO, M. C. Diversidade de fungos micorrízicos arbusculares em pomar orgânico no semiárido cearense. Ciência Rural, v. 45, n. 8, p.1480-1486, 2015. Disponível em: <http://dx.doi.org/10.1590/0103-8478cr20130097>. doi: 10.1590/0103$8478 \mathrm{cr} 20130097$.

DUVAL, C. M. A produção de flores e a agricultura familiar. Horticultura Brasileira, v. 32, n. 2, p.241-241, 2014. Disponível em: <http://dx.doi.org/10.1590/S010205362014000200022>. doi: 10.1590/S0102-05362014000200022. 
EMBRAPA. Empresa Brasileira de Pesquisa Agropecuária. Centro Nacional de Pesquisa de Solos. Manual de métodos e análise de solo. 2ed. Rio de Janeiro-RJ, 1997, 212p.

EMBRAPA. Empresa Brasileira de Pesquisa Agropecuária. Sistema brasileiro de classificação de solo. Brasília: Centro Nacional de Pesquisa de Solos, 2006.

GERDEMANN, J. W.; NICOLSON, T. H. Spores of mycorrhizae Endogone species extracted from soil by wet sieving and decanting. Transactive British Mycology Society, v. 46 n. 2, p. 235-244, 1963. Disponível em: <https://doi.org/10.1016/S0007-1536(63)80079-0>. doi: 10.1016/S00071536(63)80079-0.

HEITOR, L. C.; FREITAS, M. S. M.; BRITO, V. N.; CARVALHO, A. J. C.; MARTINS, M. A. Crescimento e produção de capítulos florais de calêndula em resposta à inoculação micorrízica e fósforo. Horticultura Brasileira, v. 34, n. 1, p.26-30, 2016. Disponível em: <http://dx.doi.org/10.1590/S0102-053620160000100004>. doi: 10.1590/S0102-053620160000100004.

INSTITUTO AGROPOLOS. Disponível em: <www.institutoagropolos.org.br>. Acesso em 20 de setembro de 2017.

JUNQUEIRA, A. H.; PEETZ, M. da S. O setor produtivo de flores e plantas ornamentais do Brasil, no período de 2008 a 2013: atualizações, balanços e perspectivas. Revista Brasileira de Horticultura Ornamental, v. 20, n. 2, p. 115120, 2014. Disponível em: <http://www.uesb.br/flower/florbrasil.pdf>.

KÖHL, L.; HEIJDEN, M. G. A. V. D. H. Arbuscular mycorrhizal fungal species differ in their effect on nutrient leaching. Soil Biology and Biochemistry, v. 94, p.191-199, 2016. Disponível em: <https://doi.org/10.1016/j.soilbio.2015.11.019>. doi: 10.1016/j.soilbio.2015.11.019.

KOSKE R. E.; GEMMA, J. N. A modified procedure for staining roots to detect VA mycorrhizas. Mycological Research, v. 92, n. 4, p. 486-505, 1989. Disponível em: $<$ https://doi.org/10.1016/S0953-7562(89)80195-9>. doi: 10.1016/S09537562(89)80195-9.

MARTINS, R. M. S.; MELLONI, R.; MELLONI, E. G. P. Crescimento micelial de fungos micorrízicos arbusculares e formação de micorriza em solo contaminado por cádmio. Revista Scientia Agraria, v. 18, n. 3, p. 48-60, 2017. Disponível em: <http://dx.doi.org/10.5380/rsa.v18i3.51122>. doi: 10.5380/rsa.v18i3.51122.

MCGONIGLE, T. P.; MILLER, M. H.; EVANS, D. G.; FAIRCHILD, G. L.; SWAN, J. A. A new method which gives an objective measure of colonization of roots by vesicular-arbuscular mycorrhizal fungi. New Phytologist, v. 115, n. 3, p. 495-501, 1990. Disponível em: <http://dx.doi.org/10.1111/j.1469-8137.1990.tb00476.x>. doi: 10.1111/j.1469-8137.1990.tb00476.x. 
MIRANDA, E. M. de; SILVA, E. M. R. da; SAGGIN JÚNIOR, O. J. Mycorrhizal inoculation and phosphate fertilizer in the production of seedlings of the forage peanut. Revista Ciência Agronômica, v. 47, n. 2, p.240-246, 2016. Disponível em: <http://dx.doi.org/10.5935/1806-6690.20160028>. doi: 10.5935/18066690.20160028.

MOREIRA, F. M. S.; SIQUEIRA, J. O. Microbiologia e bioquímica do solo. 2 ed. Lavras: Editora UFLA, 2006. v.1. 719p.

NASCIMENTO, J. M. L. do; MENEZES, K. M. S.; QUEIROZ, M. A. Á.; MELO, A. M. Y. Crescimento inicial e composição bromatológica de plantas de pornuncia adubadas com fósforo e inoculadas com fungos micorrízicos arbusculares. Revista Brasileira de Saúde e Produção Animal, v. 17, n. 4, p.561-571, 2016. Disponível em: <http://dx.doi.org/10.1590/s1519-99402016000400001>. doi: 10.1590/s151999402016000400001.

SANTOS, R. S.; SCORIZA, R. N.; FERREIRA, J. S. Fungos micorrízicos arbusculares em diferentes coberturas florestais em Vitória da Conquista, Bahia. Floresta e Ambiente, v. 20, n. 3, p. 344-350, 2013. Disponível em: <http://dx.doi.org/10.4322/floram.2013.020>. doi: 10.4322/floram.2013.020.

SAS. SAS/STAT: users guide, release 6.03. SAS Institute Inc., Cary, 1988.

SEVERINO, C. A. M. Cultivo de rosas de corte em ambiente protegido no semiárido. Bahia: RETEC. 2007. 23 f. (Dossiê Técnico).

SILVA, E. P. da; GOMES, V. F. F.; MENDES FILHO, P. F.; SILVA JÚNIOR, J. M. T. da; NESS, R. L. L. Development and mycorrhizal colonisation in embauba seedlings fertilised with natural phosphates and organic material. Revista Ciência Agronômica, v. 47, n. 2, p.256-263, 2016. Disponível em: $<$ http://dx.doi.org/10.5935/1806-6690.20160030>. doi: 10.5935/18066690.20160030 .

SOARES, A. C. F.; MAMEDIO, I. M. P.; SOARES, A. C. F.; LIMA, F. S. Fungos micorrízicos arbusculares e composto orgânico no crescimento e nutrição de mudas de sisal. Revista Brasileira de Agroecologia, v. 12, n.1, p. 2-9, 2017. Disponível em: $<$ http://revistas.abaagroecologia.org.br/index.php/rbagroecologia/article/view/16220/12654>.

STOFFEL, S. C. G.; ARMAS, R. D. de; GIACHINI, A. J.; ROSSI, M. J.; GONZALEZ, D.; et al. Micorrizas arbusculares no crescimento de leguminosas arbóreas em substrato contendo rejeito de mineração de carvão. Cerne, v. 22, n. 2, p.181-188, 2016. Disponível em: <http://dx.doi.org/10.1590/01047760201622021969>. doi: 10.1590/01047760201622021969. 